Article

\title{
Design and Study of a Novel Thermal-Resistant and Shear-Stable Amphoteric Polyacrylamide in High-Salinity Solution
}

\author{
Caili Dai *, Zhongliang Xu, Yining Wu, Chenwei Zou, Xuepeng Wu, Tao Wang, Xu Guo and \\ Mingwei Zhao * \\ School of Petroleum Engineering, State Key Laboratory of Heavy Oil Processing, China University of \\ Petroleum (East China), Qingdao 266580, China; X18353240389@163.com (Z.X.); wuyining@126.com (Y.W.); \\ zoucwupc@163.com (C.Z.); wuxuepeng@163.com (X.W.); wangtao_oilchem@163.com (T.W.); \\ guoxu5597@163.com (X.G.) \\ * Correspondence: daicl@upc.edu.cn or daicl306@163.com (C.D.); zhaomingwei@upc.edu.cn (M.Z.); \\ Tel.: +86-532-8698-1183 (C.D.); +86-532-8698-1183 (M.Z.)
}

Received: 2 June 2017; Accepted: 17 July 2017; Published: 21 July 2017

\begin{abstract}
Water-soluble polymers are widely used in oilfields. The rheological behaviors of these polymers in high-salinity solution are very important for stimulation of high-salinity reservoirs. In this work, a novel thermal-resistant and shear-stable amphoteric polyacrylamide (PASD), prepared from acrylamide (AM), sodium styrene sulfonate (SSS), and acryloxyethyl trimethylammonium chloride (DAC) monomers, was prepared by free-radical polymerization in high-salinity solution. The amphoteric polyacrylamide was characterized by Fourier transform infrared (FTIR) spectroscopy, nuclear magnetic resonance spectroscopy $\left({ }^{1} \mathrm{H}\right.$ NMR), elemental analysis, thermogravimetric analysis (TG), and scanning electron microscopy (SEM). The amphoteric polyacrylamide exhibited excellent salinity tolerance. The slow increase in apparent viscosity of the polymer with increase in salinity was interesting. The amphoteric polyacrylamide showed perfect temperature resistance in high-salinity solution. The viscosity retention reached $38.9 \%$ at $120{ }^{\circ} \mathrm{C}$ and was restored to $87.8 \%$ of its initial viscosity when temperature was decreased to room temperature. The retention ratio of apparent viscosity reached $49.7 \%$ at $170 \mathrm{~s}^{-1}$ and could still retain it at $25.8 \%$ at $1000 \mathrm{~s}^{-1}$. All these results demonstrated that PASD had excellent thermal-resistance and shear-stability in high-salinity solution. We expect that this work could provide a new strategy to design polymers with excellent salinity-tolerance, thermal-resistance, and shear-stability performances.
\end{abstract}

Keywords: amphoteric polyacrylamide; high-salinity solution; thermal-resistance; shear-stability

\section{Introduction}

Water-soluble polymers have been intensively explored, due to their practical importance as viscosity-enhancing agents, flocculating agents, food additives, etc. [1,2]. Development of new types of water-soluble polymers is an important subject in current research. Polyacrylamide has been successfully employed in wastewater treatment, the papermaking industry, and the oil industry due to its thickening ability, flocculation and rheological behaviors [3,4]. However, the properties of the polymeric solution render it sensitive to changes in the external environment, such as temperature and salinity [5]. Improving the resistance of polyacrylamide to its external environment is an effective way to broaden its applications in harsh environmental conditions.

Water-soluble polymers have been successfully employed in oilfields. To date, polyacrylamide (PAM) and partially hydrolyzed polyacrylamide (HPAM) have been the most widely used polymers in oil fields, such as in chemical flooding, drilling fluids, fracturing fluids, clay stabilizers, and other 
EOR technologies [6-9]. However, there are some limitations associated with the application of water-soluble polymers in reservoirs under harsh conditions. PAM and HPAM show serious losses in their apparent viscosities, due to the hydrolysis of $-\mathrm{CONH}_{2}$ groups above $70{ }^{\circ} \mathrm{C}$ [10]. Multivalent metal ions react with the $-\mathrm{COO}^{-}$groups, leading to flocculation in high-salinity solutions $[11,12]$. High shear rates can destroy the linear chain structures of PAM and HPAM [13]. PAM and HPAM are not suitable for stimulation of high temperature or high-salinity reservoirs. Pioneering work indicated that acrylamide (AM) copolymerized with suitable ionic monomers could significantly improve its performance [14-16]. A large number of acrylamide-based copolymers synthesized for EOR were based on this strategy [17]. Various ionic monomers were copolymerized with AM, in order to modify the properties of the copolymers $[18,19]$, which included anionic as well as cationic monomers. The anionic monomers included sodium-2-acrylamido-2-methylpropane sulfonate (NaAMPS), sodium acrylate (NaAA), and sodium-3-acrylamido-3-methylbutanoate (NaAMB) [20-22]. The cationic monomers included 2-(acrylamido)-2-methylpropanetrimethylammonium chloride (AMPTAC), diallyl dimethyl ammonium chloride (DMDAAC), dimethyldodecyl (2-acrylamidoethyl) ammonium bromide (DAMAB), and 2-acrylamido-2-methylpropanedimethylammonium chloride (AMPDAC) [23-25]. The cationic or anionic polyacrylamide exhibited perfect temperature resistance and thickening ability in fresh water. Copolymers bearing only positive or negative charges possess only electrostatic repulsive forces in their molecular chains. The polymer chain expands to have a large hydrodynamic volume in fresh water. These copolymers have the highest viscosity in fresh water. However, when a cationic or an anionic acrylamide copolymer is dissolved in a saline solution, there is an obvious reduction in its viscosity. The presence of salts weakens the intramolecular repulsive interactions, the molecular chains curl, and the hydrodynamic volume shrinks. The viscosity of the traditional acrylamide copolymer reduces sharply with an increase in salinity. Still the sensitivity to salinity limits the applications of these polymers in high-salinity reservoirs.

Recently, polyampholyte has attracted a lot of attention due to its unique properties [26]. A polyampholyte contains both positive and negative charges attached to the same polymeric backbone. The viscosity of a polyampholytic solution increases with increase in salinity under certain conditions, popularly known as anti-polyelectrolyte behavior in solution [27]. Polyampholytes have a wide range of applications such as ion exchange and chelation materials to bind trace metals from drinking water, sewage treatment, paper reinforcement, soil conditioning, pigment retention, and in formulations of shampoos and hair conditioners [28,29]. Polyampholytes have also been used in petroleum explorations. For instance, He [30] synthesized an amphiphilic copolymer containing acrylamide, acrylic acid, 2-acrylamido-2-methyl propane sulfonic acid, and modified $\beta$-cyclodextrin to be an oil displacement agent, which showed good temperature resistance and oil displacement ability. Patrizio Raffa [31] also reported amphiphilic copolymers based on poly(ethylene glycol) methyl ether acrylate (PEGA) as the polymeric surfactant for applications in enhanced oil recovery. Favero [32] synthesized a high molecular-weight polyampholyte containing acrylamide, sodium acrylate, and diallyl dimethyl ammonium chloride as a fracturing fluid thickener. These studies indicate that the polyampholyte has excellent thickening ability in solution at high temperatures. However, effective thickening of a high-salinity solution is still a big challenge.

This paper presents the design and synthesis of an amphoteric polyacrylamide. This polyampholyte was synthesized by polymerization in an aqueous solution. The characteristics of the functional group decide the properties of the polymer to a great extent [33]. However, in addition to this, the reactivities of the comonomers should also be considered. The anionic monomer, sodium styrene sulfonate (SSS), possesses temperature resistant headgroups, which include both, the $-\mathrm{SO}_{3}{ }^{-}$group and the aromatic ring. Acrylamide copolymer containing SSS is expected to exhibit remarkable anti-shearing property and temperature resistance [22]. The cationic monomer, acryloxyethyl trimethyl ammonium chloride (DAC), can inhibit the hydration swelling ability of clay minerals, and its bulky side chains can boost the salinity tolerance and shear-stability [34]. Furthermore, both SSS and DAC are cheap and undergo copolymerization actively. Hence, by employing the above design strategy, the amphoteric 
polyacrylamide (PASD) was copolymerized from AM, SSS, and DAC under optimized reaction conditions. A series of experiments were carried out to investigate the structure and characteristics of the copolymer. The detailed rheological properties in high-salinity solution have also been studied.

\section{Materials and Methods}

\subsection{Materials}

AM $(99.0 \%$, AR) was purchased from Aladdin Industrial Co. Ltd. (Shanghai, China). SSS (99.0\%, AR) was purchased from Energy Chemical Co. Ltd. (Shanghai, China). DAC with a purity of $80 \mathrm{wt} \%$ in water was purchased from J\&K Scientific Co. Ltd. (Beijing, China). Ammonium persulfate (APS), sodium bisulfite $\left(\mathrm{NaHSO}_{3}\right)$, sodium chloride $(\mathrm{NaCl})$, calcium chloride $\left(\mathrm{CaCl}_{2}\right)$, magnesium chloride $\left(\mathrm{MgCl}_{2}\right)$, and ethanol $\left(\mathrm{C}_{2} \mathrm{H}_{5} \mathrm{OH}\right)$ were all of analytical reagent grade and were obtained from Sinopharm Chemical Reagent Co. Ltd. (Shanghai, China). The chemicals were used directly without further purification. Deionized water was used throughout this work.

\subsection{Synthesis of Polyampholyte PASD}

AM (20.39 g) and SSS (12.85 g) were dissolved in deionized water (102 mL). DAC (14.87 g) was added to the above solution under inert nitrogen atmosphere. $\mathrm{NaOH}$ solution (10 wt \%) was added to the above solution to adjust the $\mathrm{pH}$ to 6 . The reaction mixture was heated to $35^{\circ} \mathrm{C}$ and stirred for $30 \mathrm{~min}$. Then, the initiators APS $(0.095 \mathrm{~g})$ and $\mathrm{NaHSO}_{3}(0.040 \mathrm{~g})$ in molar ratio of $\left[\mathrm{n}(\mathrm{APS}) / \mathrm{n}\left(\mathrm{NaHSO}_{3}\right)=1.1 / 1\right.$ ] were added drop-wise. The copolymerization was carried out at $35^{\circ} \mathrm{C}$ under nitrogen atmosphere for $4 \mathrm{~h}$. After cooling to room temperature, it was washed several times with 4:1 $(v / v)$ mixture of ethanol and water, and dried at $60^{\circ} \mathrm{C}$ under vacuum. Thereafter, the sample was screened, and finally the copolymer product in powdered form was obtained. The synthesis of PASD is shown in Scheme 1.

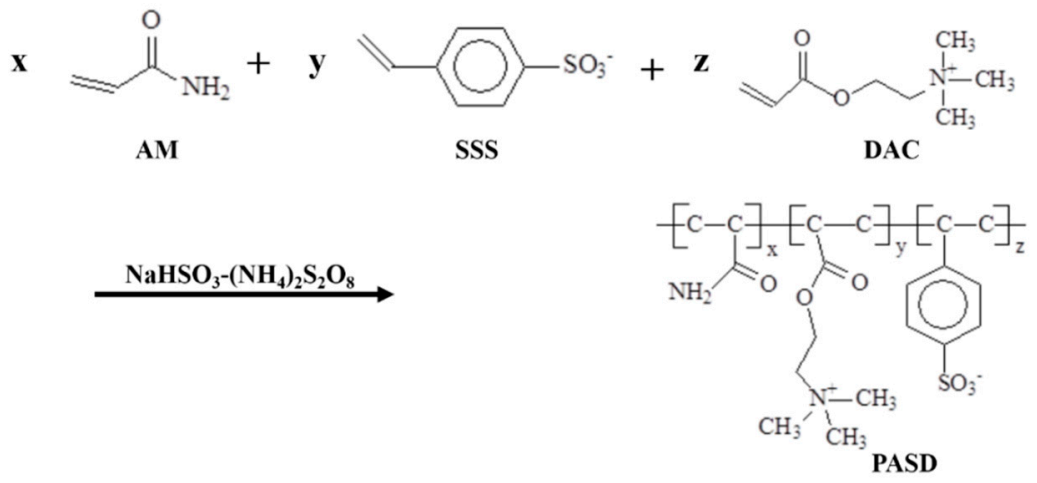

Scheme 1. Synthesis of amphoteric polyacrylamide PASD.

\subsection{Conversion Measurement}

Conversion of the monomers to the copolymer was calculated from the masses of the copolymer and monomers, determined gravimetrically. Samples were withdrawn from the reaction mixture periodically and washed several times with a $4: 1(v / v)$ mixture of ethanol and water to remove the unreacted monomers. Then, samples were dried and then weighed. The conversion of the monomers to the copolymer ( $\mathrm{C} \%$ ) was calculated using Equation (1):

$$
C \%=\left(\frac{W_{1}}{W_{2}}\right) \times\left(\frac{1}{W}\right) \times 100 \%
$$

where, $W_{1}$ and $W_{2}$ are the weights of dry polymer, reaction mixture, and $W$ is the weight percent of total monomer in initial reaction mixture. 


\subsection{Characterizations}

Fourier transform infrared (FTIR) spectrum of the dried and powdered PASD was recorded on a Nicolet 6700 FTIR spectrometer (Nicolet, WI, USA) following the KBr-disk method. The sample was mixed with $\mathrm{KBr}$ powder, pressed into a disk, and then dried at $105^{\circ} \mathrm{C}$ for $24 \mathrm{~h}$ prior to the analysis. The spectrum was recorded at room temperature in the range of $4000-500 \mathrm{~cm}^{-1}$, with minimum 32 scans at a resolution of $4 \mathrm{~cm}^{-1}$. Nuclear magnetic resonance spectrum $\left({ }^{1} \mathrm{H}\right.$ NMR) of PASD (in $\left.\mathrm{D}_{2} \mathrm{O}\right)$ was obtained on a Bruker AV III-400 NMR spectrometer (Bruker Biospin, Switzerland) that operated at $400 \mathrm{MHz}$. Elemental analysis was performed using Vario EL-III elemental analyzer (Elementary Analyze System GmbH, Hanau, Germany). Thermogravimetric analysis (TG) of PASD was conducted on the STA 449 F3 Jupiter instrument (Netzsch, Bavaria, Germany). The sample was heated at a rate of $10.0^{\circ} \mathrm{C} / \mathrm{min}$ from 30 to $600{ }^{\circ} \mathrm{C}$ under nitrogen atmosphere. The surface morphology of PASD in a high-salinity solution was investigated by scanning electron microscopy (SEM, S-4800, Hitachi, Tokyo, Japan). The sample contained 2\% PASD in 150,000 mg/ $\mathrm{L} \mathrm{NaCl}$ solution. The solution was dropped onto a special glass and rapidly frozen in liquid nitrogen. The surface of the sample was observed using a scanning electron microscope that operated at an accelerating voltage of $5 \mathrm{kV}$.

\subsection{Properties of the PASD}

\subsubsection{Salinity-Tolerance Test}

The salinity tolerance of PASD solution was tested using $\mathrm{NaCl}, \mathrm{CaCl}_{2}$, and $\mathrm{MgCl}_{2}$. The apparent viscosities of polyampholyte solutions in different saline concentrations were determined by HAAKE MARS 60 rotational rheometer (Thermo, Karlsruhe, Germany). The apparent viscosities were determined using the cone/plate geometry (diameter $35 \mathrm{~mm}$, angle $1^{\circ}$, plate to plate gap $0.052 \mathrm{~mm}$ ) under a shear rate of $7.34 \mathrm{~s}^{-1}$ at room temperature.

\subsubsection{Temperature Resistance Test}

The viscosities of $2.5 \%$ PASD in $150,000 \mathrm{mg} / \mathrm{L} \mathrm{NaCl}$ solution at both room temperature and high temperatures were determined using HAAKE MARS 60 rotational rheometer. The steady shear viscosities were obtained at a heating rate of $3{ }^{\circ} \mathrm{C} / \mathrm{min}$ in the temperature range from 25 to $120^{\circ} \mathrm{C}$, under a shear rate of $170 \mathrm{~s}^{-1}$, using the high pressure test system (D300 cell, PZ38 rator).

\subsubsection{Shear Stability Test}

The shear resistance tests were performed at different shear rates and the shear stress was measured from 0.1 to $1000 \mathrm{~s}^{-1}$. The sample containing 3\% PASD in 150,000 mg/L NaCl solution was tested using HAAKE MARS 60 rotational rheometer, with coaxial cylinder geometries (CC41/Ti Rotor) at $25{ }^{\circ} \mathrm{C}$.

\section{Results and Discussion}

\subsection{Effects of Reaction Conditions}

The effects of reaction conditions on the conversion of the monomers to PASD were investigated by the single factor method. The curves for conversion versus time under different reaction conditions are shown in Figure 1. From Figure 1a, it is evident that the polymerization rate increased with increase in monomer concentration. The more number of active molecules present in a solution containing higher monomer concentration increased the probability of reaction. There was a dramatic increase in temperature and viscosity, which indicated that gelation increased with increase in monomer concentration.

Initiator plays a key role in polymerization. Figure $1 \mathrm{~b}$ shows conversion as a function of time at different initiator concentrations. The polymerization rate increased constantly as the concentration of 
the initiator increased. The number of free radicals and active aggregates increased with increase in initiator concentration. An initiator concentration of $0.3 \mathrm{wt} \%$ was found to be optimum.

Figure 1c shows the influence of $\mathrm{pH}$ on the conversion of monomers to PASD. It was clear from the figure that a lower or higher $\mathrm{pH}$ value decreased the polymerization rate. The maximum polymerization rate and final conversion were achieved when the $\mathrm{pH}$ was 6 .

The effect of temperature on the conversion of monomers to PASD can be seen in Figure 1d. The polymerization rate increased with increase in temperature. This could be attributed to the rapid increase in the decomposition rate of the initiator as well as an increase in the propagation rate constant. The polymerization occurred explosively at a very high temperature. However, at a very low temperature, the yield and molecular weight of the copolymer were not satisfactory. The optimum temperature for the polymerization reaction was found to be $35^{\circ} \mathrm{C}$.

A higher final conversion and a stable reaction rate are very important for the preparation of the polymer. Finally, the optimal reaction conditions were: a total monomer concentration of $30 \mathrm{wt} \%$, initiator concentration of $0.3 \mathrm{wt} \%, \mathrm{pH}$ of 6 , and a reaction temperature of $35{ }^{\circ} \mathrm{C}$. A near-linear relationship between the conversion-time curves and the highest final conversion could be reached under these reaction conditions. The near-linear relationship of the conversion-time curves is beneficial for industrial production.
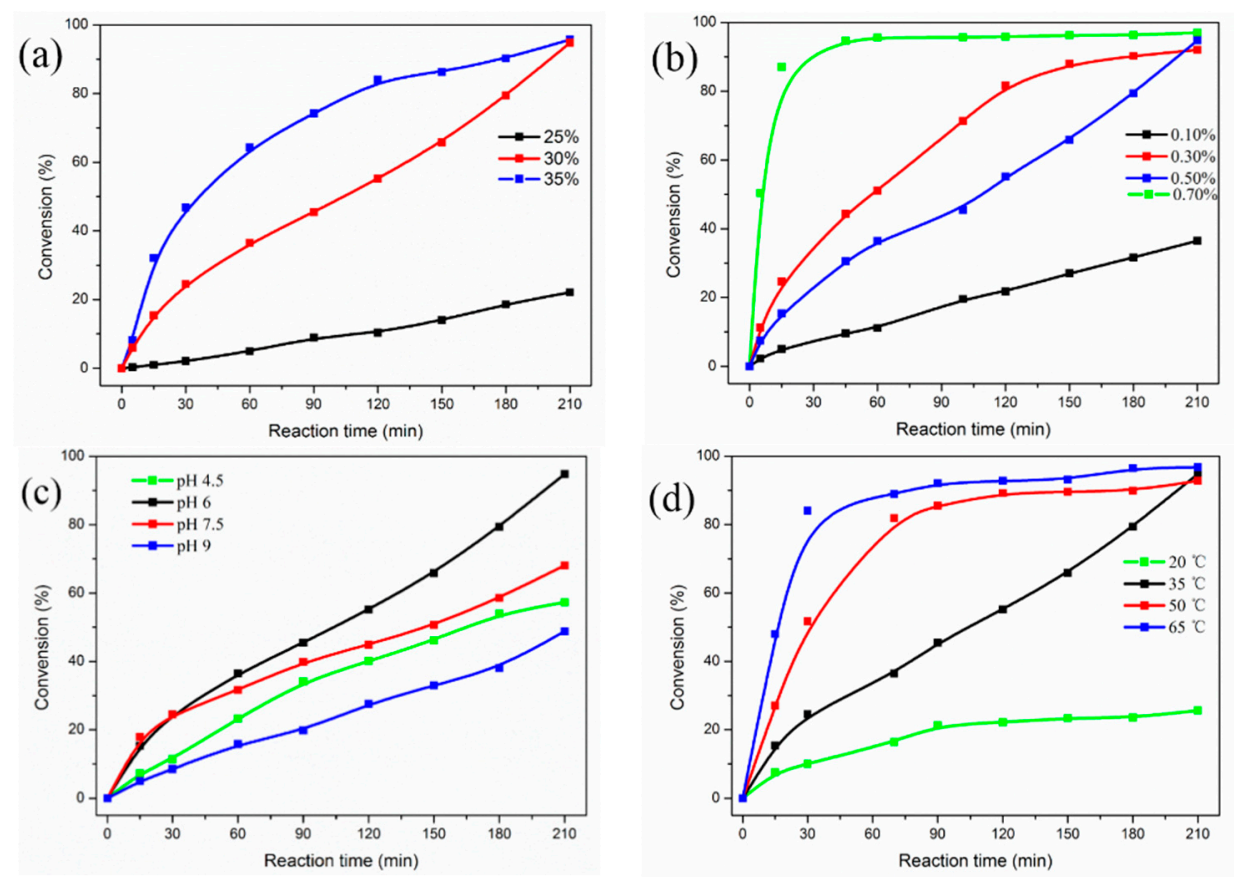

Figure 1. Conversion versus time curves showing the effects of reaction conditions on conversion. Effect of: (a) total monomer concentration, (b) initiator concentration, (c) $\mathrm{pH}$, and (d) reaction temperature.

\subsection{Characterization of Copolymers}

The FTIR spectrum of the synthesized PASD copolymer is shown in Figure 2. The peak at $1685 \mathrm{~cm}^{-1}$ could be assigned to the $\mathrm{C}=\mathrm{O}$ stretching vibrations of the $-\mathrm{CONH}_{2}$. The broad intense peak at $3435 \mathrm{~cm}^{-1}$ was due to the $\mathrm{N}-\mathrm{H}$ stretching vibrations of the $-\mathrm{CONH}_{2}$ group. These characteristic peaks confirmed the successful introduction of AM into the copolymer. Characteristic peaks at 2930 and $2871 \mathrm{~cm}^{-1}$ were attributed to the stretching vibrations of $-\mathrm{CH}_{3}$. The peaks at 2850 and $1410 \mathrm{~cm}^{-1}$ were assigned to the $-\mathrm{CH}_{2}-$ groups on the polymeric chain, whereas the stretching vibrations of the ester $-\mathrm{COO}^{-}$were observed at $1735 \mathrm{~cm}^{-1}$. The presence of these peaks indicated that DAC was successfully incorporated into PASD. Peaks at 1036 and $1170 \mathrm{~cm}^{-1}$ were characteristic of the $-\mathrm{SO}_{3}{ }^{-}$group. The peak at $620 \mathrm{~cm}^{-1}$ also proved the presence of $-\mathrm{SO}_{3}{ }^{-}$group. Characteristic 
peaks of $C=C$ of benzene ring appeared at 1493 and $1454 \mathrm{~cm}^{-1}$. Peaks at 860 and and $820 \mathrm{~cm}^{-1}$ were characteristic of para-substituted aromatic rings. The appearance of these peaks suggested the successful copolymerization of DAC. The FTIR spectrum of the copolymer confirmed that the polyampholyte PASD was synthesized successfully.

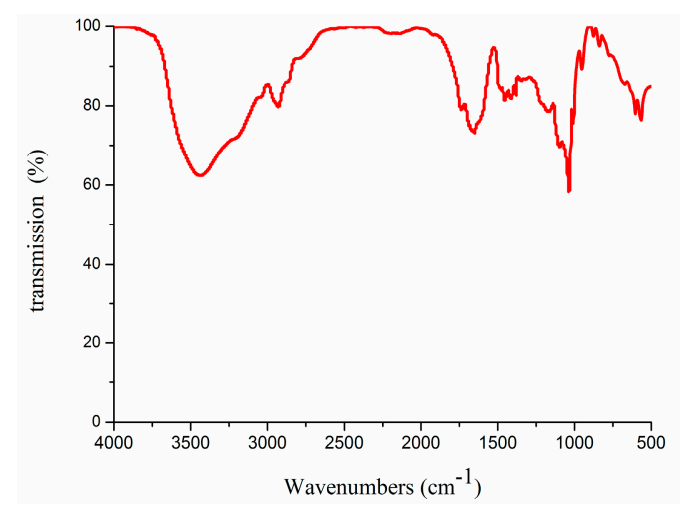

Figure 2. FTIR spectrum of PASD.

${ }^{1} \mathrm{H}$ NMR analysis further verified the successful preparation of PASD. The ${ }^{1} \mathrm{H}$ NMR spectrum of PASD is shown in Figure 3. The peak at 7.91 ppm was due to the protons of the aromatic ring, indicating the presence of SSS. Peaks at 3.28 and $3.11 \mathrm{ppm}$ were assigned to the $-\mathrm{CH}_{2}-$ groups of DAC attached to $-\mathrm{N}\left(\mathrm{CH}_{3}\right)_{3}{ }^{+}$, whereas the characteristic peak of methyl $-\mathrm{CH}_{3}$ groups of DAC appeared at $3.44 \mathrm{ppm}$.

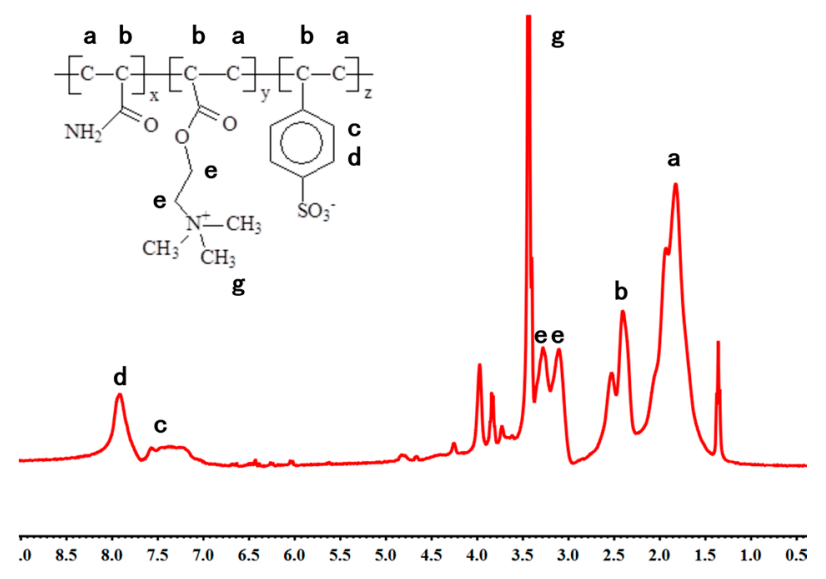

Figure $3 .{ }^{1} \mathrm{H}$ NMR spectrum of PASD.

Elemental analysis was conducted to evaluate the components of PASD. At high temperature, in the presence of oxygen and catalyst, $\mathrm{S}$ and $\mathrm{N}$ elements of the sample were oxidized to $\mathrm{SO}_{2}$ and $\mathrm{N}_{2}$, respectively. The gases were separated in the chromatographic column by the carrier gas. Finally, the different elements were detected in the thermal conductivity cell and analyzed. Based on the principles of mass conservation and the element conservation, the ratios of different monomers in the copolymer were calculated. The results are shown in Table 1 . The composition of the resultant copolymer was based on several factors, which included monomer concentrations and their corresponding reactivity ratios. It was observed that PASD contained an almost equivalent number of cationic and anionic monomers. The properties and rheological behavior of PASD in a high-salinity solution are mainly discussed in the subsequent sections. 
Table 1. Elemental analysis and composition of PASD.

\begin{tabular}{|c|c|c|c|c|c|c|c|c|c|c|c|}
\hline \multirow[b]{2}{*}{ Sample } & \multicolumn{3}{|c|}{ Comonomer used } & \multicolumn{3}{|c|}{$\begin{array}{l}\text { Comonomer ratios in } \\
\text { the feed (mole \%) }\end{array}$} & \multicolumn{2}{|c|}{$\begin{array}{l}\text { Percentages of } \\
\text { elements (wt \%) }\end{array}$} & \multicolumn{3}{|c|}{$\begin{array}{l}\text { Comonomer ratios in } \\
\text { the copolymer (mole \%) }\end{array}$} \\
\hline & $\mathrm{A}$ & $\mathrm{B}$ & $\mathrm{C}$ & A & B & $\mathrm{C}$ & $\mathrm{S}$ & $\mathrm{N}$ & $\mathrm{A}$ & $\mathrm{B}$ & $\mathrm{C}$ \\
\hline PASD & AM & SSS & DAC & 70 & 15 & 15 & 4.84 & 9.93 & 64.9 & 17.6 & 17.5 \\
\hline
\end{tabular}

The thermogravimetric (TG) and differential thermogravimetric (DTG) curves of PASD are shown in Figure 4. In general, PASD experienced three stages of weight loss in both TG and DTG. A weight loss of $5.49 \%$ in the first stage in the temperature range of $30-198^{\circ} \mathrm{C}$ could be attributed to the removal of intermolecular or intramolecular moisture. The second stage, with a weight loss of $11.94 \%$, occurred in the temperature range of $198-326^{\circ} \mathrm{C}$, due to the decomposition of amide groups. The third stage accounted for a weight loss of $48.66 \%$ in the temperature range of $326-500{ }^{\circ} \mathrm{C}$, as a result of the decomposition of the quaternary ammonium salt and benzenesulfonamide groups. The residue of PASD at $600{ }^{\circ} \mathrm{C}$ was $30 \%$. Compared to the TG curve of HPAM reported earlier [35], the decomposition temperature of PASD was found to be higher. The aromatic ring made PASD extraordinary rigid and stable. The $-\mathrm{SO}_{3}{ }^{-}$group was also stable at high temperature. The presence of aromatic rings and $-\mathrm{SO}_{3}{ }^{-}$groups significantly improved the thermal stability of PASD.

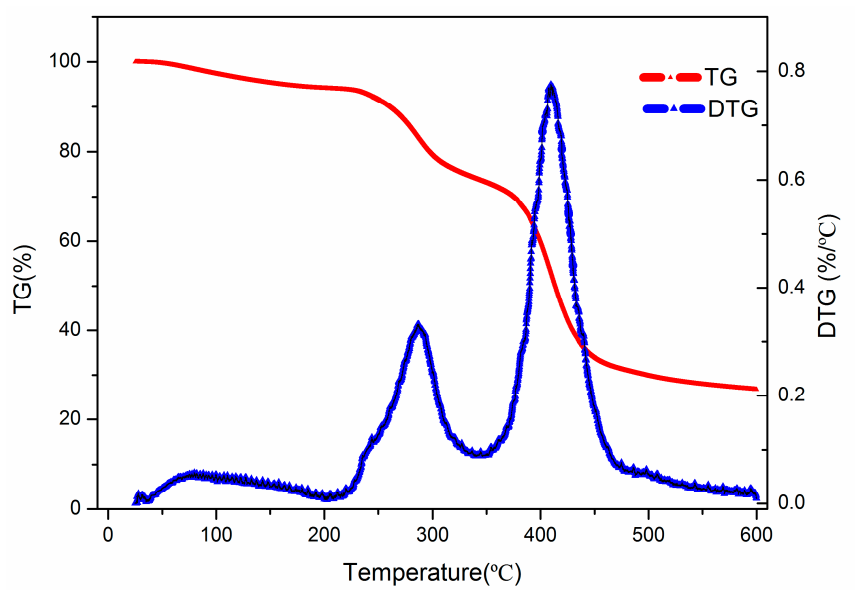

Figure 4. TG and DTG curves of PASD.

The SEM images of $2 \%$ copolymer in a high-salinity $(150,000 \mathrm{mg} / \mathrm{L}) \mathrm{NaCl}$ solution are shown in Figure 5. The microstructure of PASD polymer can be seen clearly in Figure 5a. The amphoteric polyacrylamide showed a fish-bone framework structure, with a completely expanded polymeric coil in the high-salinity solution. The compact microscopic structures can be seen in Figure 5b. A large number of intermolecular linkages could be seen between the polymer chains and the high hydrodynamic volume was a result of these dense intermolecular linkages. The perfect thickening ability of the amphoteric polyacrylamide could be mainly attributed to the expansion of the polymeric coil and the large number of intermolecular linkages in the high-salinity solution. The anti-polyelectrolyte behavior of PASD was strongly demonstrated by SEM. 

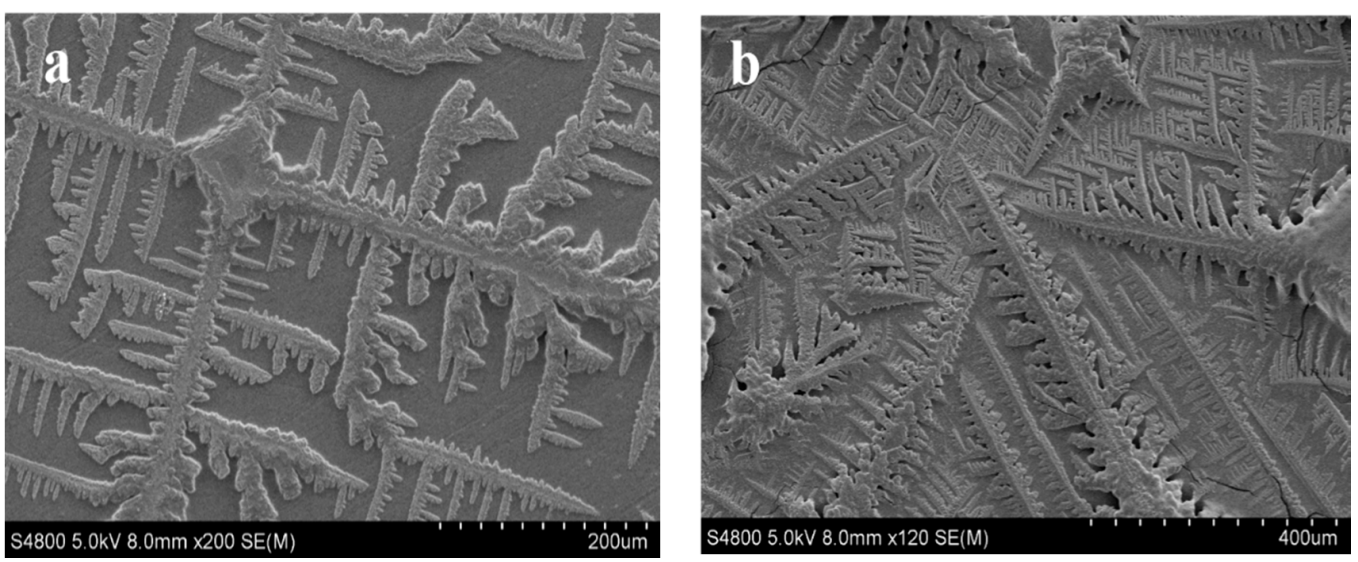

Figure 5. Scanning electron microscopic (SEM) images of PASD in salinity solution: (a) sample solution at $200 \mu \mathrm{m}$, (b) sample solution at $400 \mu \mathrm{m}$.

\subsection{Salinity Tolerance Ability}

The apparent viscosities of PASD solutions at different salinities are shown in Figure 6. The polymer concentrations were $1.5 \%$ and $2.0 \%$. The viscosity of PASD solution increased slowly with increase in salinity. This was contrary to the traditional AM copolymer, where the viscosity reduced drastically with increase in salinity. Compared to the traditional AM copolymer, PASD showed excellent anti-polyelectrolyte behavior in high-salinity solutions.

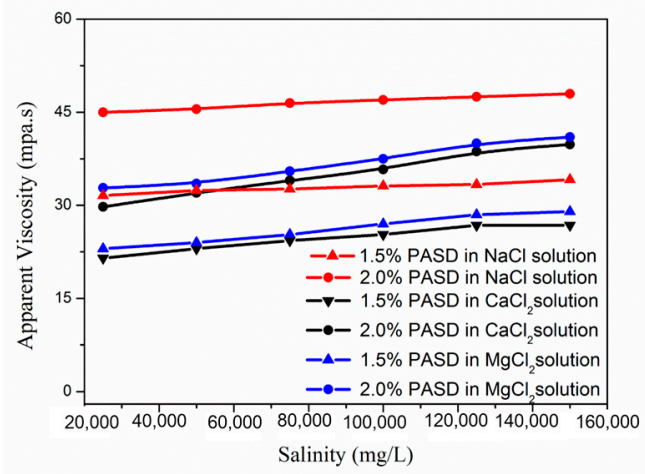

Figure 6. Effect of salinity concentration on apparent viscosity of PASD solution.

The mechanism of thickening is shown in Figure 7. The amphoteric polyacrylamide exhibited strong intramolecular electrostatic interactions, due to the co-existence of positive and negative charges. The intramolecular electrostatic interactions dominated the polyampholytic properties and the charges prevented the expansion of the polymeric coil in fresh water. The hydrodynamic volume reduced drastically, which lowered the apparent viscosity of PASD solution. The inorganic ions had stronger electrostatic interactions with the ionic monomer. With increase in salinity, the intramolecular interactions reduced. The hydrodynamic volume of PASD increased, and the apparent viscosity increased slightly. With further increase in salinity, the intermolecular interactions dominated the polyampholytic properties. The intermolecular interactions strongly increased the apparent molecular weight of the system, as depicted by SEM image in Figure $5 \mathrm{~b}$. Thus, the apparent viscosity of PASD continued to increase in high-salinity solutions. It was observed that the overall viscosity of PASD was lower than that of the acrylamide copolymer reported previously [35]. This could be simply due to the lower molecular weight of PASD. It was more likely that the coil was greatly shrunk due to the large number of intramolecular crosslinks, resulting in an apparent lowering of molecular weight. It should be noted that the hydrodynamic volume would continue to increase even in media 
of higher ionic strength. This excellent salinity tolerance of PASD can be very useful in production of high-salinity reservoirs.

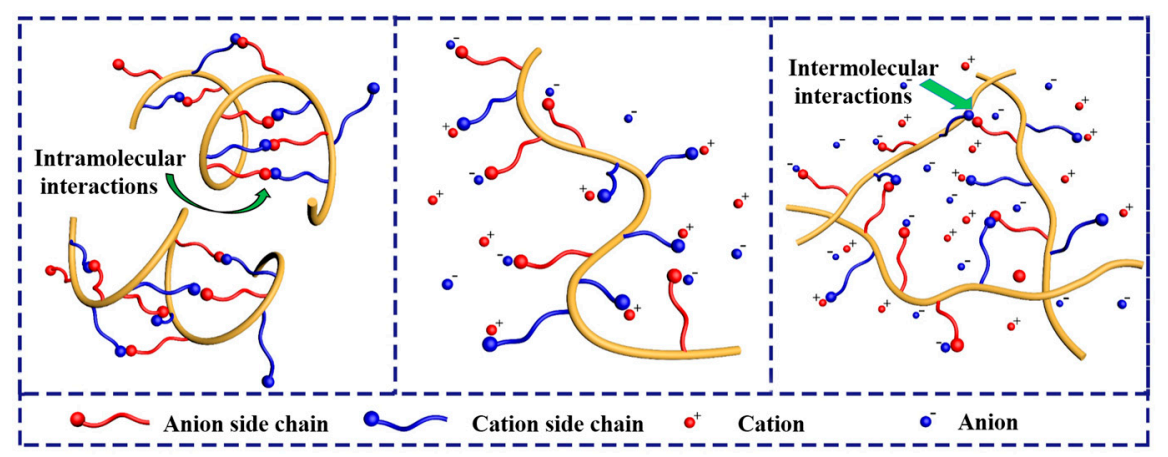

(a) Fresh water

(b) Low-salinity concentration

(c) High-salinity concentration

Figure 7. Thickening mechanism of PASD chains in (a) fresh water; (b) the low-salinity solution; and (c) the high-salinity solution.

\subsection{Temperature Resistance Ability}

The effect of temperature on the apparent viscosity of PASD in $\mathrm{NaCl}$ solution is shown in Figure 8. The apparent viscosity reduced gradually with increase in temperature. The retention rate of the copolymer solution reached $38.9 \%$ at $120{ }^{\circ} \mathrm{C}$, with a viscosity of $37 \mathrm{mPa} \cdot \mathrm{s}$. The $-\mathrm{SO}_{3}{ }^{-}$ headgroup displayed stronger hydrogen bonding than the $-\mathrm{COO}^{-}$group, resulting in remarkable thermal stability at high temperature. The copolymer solution showed outstanding thermal stability and thickening ability at high temperature, due to the presence of benzene rings and sulfonate groups. With decrease in temperature, the apparent viscosity began to increase, and the viscosity reached an $87.8 \%$ retention rate, compared to its initial viscosity at $25^{\circ} \mathrm{C}$. PASD had excellent temperature resistance in high-salinity solution.

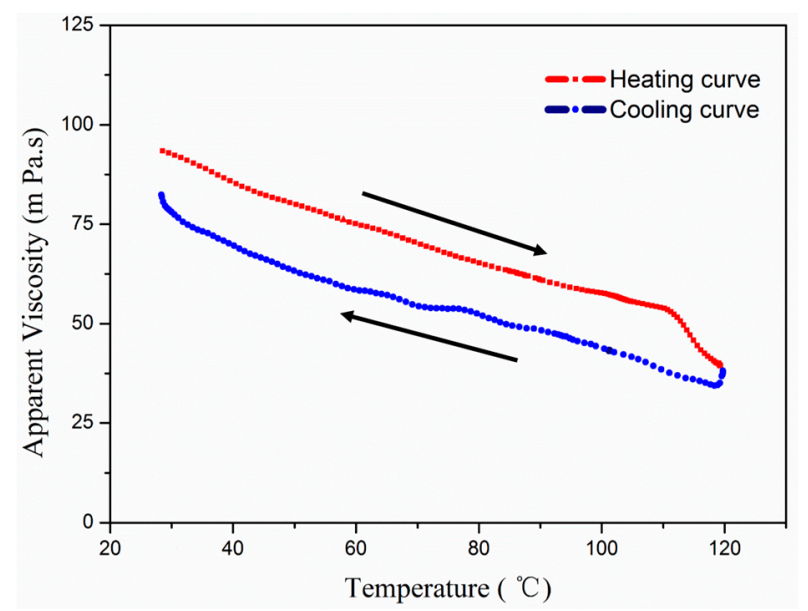

Figure 8. Effect of temperature on the apparent viscosity of PASD in $\mathrm{NaCl}$ solution.

\subsection{Shear Stability}

The shear stability of PASD in $\mathrm{NaCl}$ solution was investigated, as shown in Figure 9. The relation between shear rate and shear stress was calculated using Equation (2). The consistency coefficient $(\mathrm{k})$ and power law exponent $(n)$ were obtained from Figure $9 \mathrm{~b}$, which showed the relationship between 
shear rate and shear stress on the log scale. The $n$ and $\kappa$ values of amphoteric polyacrylamide were 0.74 and $0.57 \mathrm{~Pa} \cdot \mathrm{s}^{0.74}$, respectively. The PASD solution exhibited an obvious pseudoplastic fluid behavior.

$$
\tau=\kappa \gamma^{n}
$$

where $\tau$ was shear stress, Pa; $\gamma$ was shear rate, $\mathrm{s}^{-1} ; \kappa$ was the consistency coefficient, $\mathrm{Pa} \cdot \mathrm{s}^{\mathrm{n}}$; and $n$ was power law exponent.
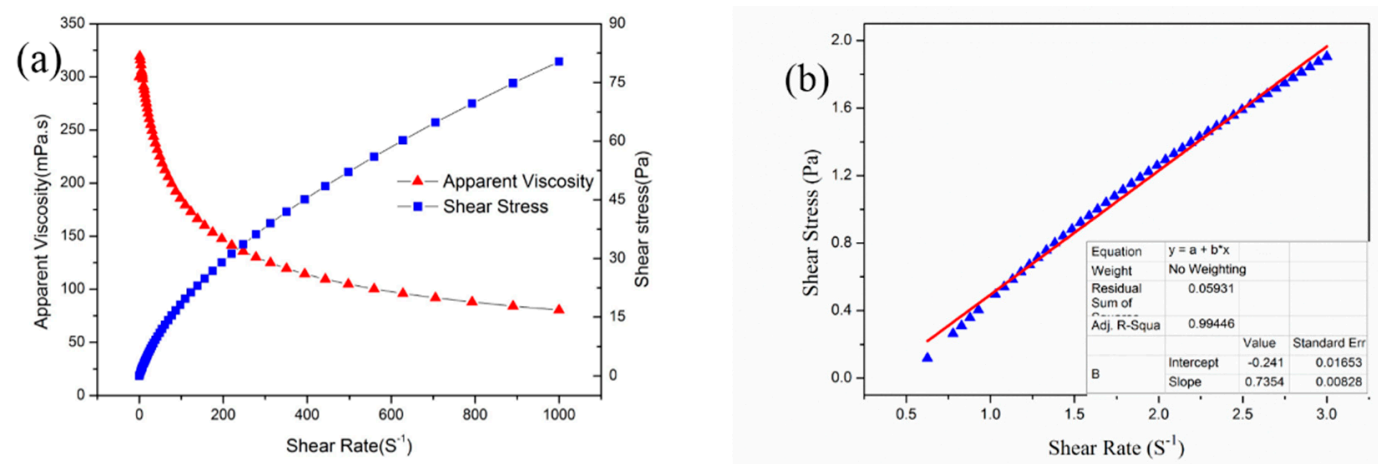

Figure 9. Shear resistance of PASD in $\mathrm{NaCl}$ solution: (a) effect of shear rate on apparent viscosity of sample; (b) effect of shear rate on shear stress in log-log scale.

It became clear that the apparent viscosity of polyampholyte solution decreased sharply at a shear rate of 3.7-200 s$~ s^{-1}$. However, there was a slight change in the apparent viscosity at a higher shear rate of $200-1000 \mathrm{~s}^{-1}$. PASD showed a viscosity retention rate of $25.8 \%$ at $1000 \mathrm{~s}^{-1}$. The intermolecular linkages played a key role in the thickening ability of PASD in a high-salinity solution. A high shear rate had less impact on the on the breaking of the intermolecular linkages in the polymer. Hence, PASD displayed extraordinary shear stability in a high-salinity solution and high viscosity retention at $1000 \mathrm{~s}^{-1}$.

\section{Conclusions}

In this study, a novel amphoteric polyacrylamide, PASD, was successfully synthesized through free-radical polymerization in aqueous solution. The effects of reaction conditions on the reaction rate and final conversion were investigated using the single factor method. The optimal reaction conditions were established at mild conditions: a total monomer concentration of $30 \mathrm{wt} \%$, initiator concentration of $0.3 \mathrm{wt} \%$, $\mathrm{pH}$ of 6 , and a reaction temperature of $35^{\circ} \mathrm{C}$. FTIR and ${ }^{1} \mathrm{H}-\mathrm{NMR}$ spectroscopic analyses proved qualitatively that the structure of PASD included AM, DAC, and SSS moieties. Elemental analysis was used to quantitatively determine the composition of PASD. The mole ratios of the monomers, AM:SSS:DAC, in the copolymer were $64.9 \%: 17.6 \%: 17.5 \%$. This implied that PASD contained almost an equivalent number of cationic and anionic monomers. The TG characterization was used to test the thermal stability of PASD, it showed that the PASD had a higher decomposition temperature compared to traditional polyacrylamide due to the presence of an aromatic ring and $-\mathrm{SO}_{3}{ }^{-}$groups. From the results of salinity tolerance test and element analysis, besides the SEM images of PASD in high-salinity solution, the thickening mechanism of PASD in high-salinity solutions was proposed. This unique polyampholyte structure also showed enhanced temperature resistance and shear stability in high-salinity solution. The viscosity retention reached $38.9 \%$ at $120{ }^{\circ} \mathrm{C}$. The retention ratio of apparent viscosity reached $49.7 \%$ at $170 \mathrm{~s}^{-1}$ and could still retain it at $25.8 \%$ at $1000 \mathrm{~s}^{-1}$. PASD has excellent thickening ability in high-salinity solution. It may be widely applied in drilling fluid and superabsorbent polymers. PASD also has remarkable salinity tolerance, temperature resistance, and shear stability. It has great advantages for the additives of flocculants, coatings and cosmetics. 
Acknowledgments: This work was supported by the National Key Basic Research Program (2015CB250904), National Science Fund (U1663206, 51425406), Chang Jiang Scholars Program (T2014152), Climb Taishan Scholar Program in Shandong Province (tspd20161004), and the Fundamental Research Funds for the Central Universities (15CX08003A).

Author Contributions: Caili Dai and Mingwei Zhao conceived and designed the experiments; Zhongliang Xu performed the experiments; Yining $\mathrm{Wu}$ revised the paper; Chenwei Zou designed the mechanism diagram; Xuepeng Wu contributed to FTIR and ${ }^{1} \mathrm{H}$ NMR spectral analysis; Tao Wang and Xu Guo provided the materials.

Conflicts of Interest: The authors declare no conflict of interest.

\section{References}

1. Kutsevol, N.; Guenet, J.M.; Melnik, N.; Sarazin, D.; Rochas, C. Solution properties of dextran-polyacrylamide graft copolymers. Polymer 2006, 47, 2061-2068. [CrossRef]

2. Tripathy, T.; De Ranjan, B. Flocculation: A New Way to Treat the Waste Water. J. Phys. Sci. 2006, 10, 93-127.

3. Siyam, T. Development of acrylamide polymers for the treatment of waste water. Des. Monomers Polym. 2001, 4, 107-168. [CrossRef]

4. Tha, A.; Agrawal, S.; Mishra, A.; Rai, J.P. Synthesis, Characterization and Flocculation Efficiency of Poly(acrylamide-co-acrylic acid) in Tannery Waste-water. Iran. Polym. J. 2001, 10, 85-90.

5. Caulfield, M.J.; Qiao, G.G.; Solomon, D.H. Some aspects of the properties and degradation of polyacrylamides. Chem. Rev. 2002, 102, 3067-3084. [CrossRef] [PubMed]

6. Jung, J.C.; Zhang, K.; Bo, H.C.; Choi, H.J. Rheology and polymer flooding characteristics of partially hydrolyzed polyacrylamide for enhanced heavy oil recovery. J. Appl. Polym. Sci. 2013, 127, 4833-4839. [CrossRef]

7. Liu, X.; Liu, K.; Gou, S.; Liang, L.; Cheng, L.; Guo, Q. Water-Soluble Acrylamide Sulfonate Copolymer for Inhibiting Shale Hydration. Ind. Eng. Chem. Res. 2014, 53, 2903-2910. [CrossRef]

8. Pu, W.F.; Liu, R.; Wang, K.; Li, K.; Yan, Z.; Li, B.; Zhao, L. Water soluble core-shell hyperbranched polymers for enhanced oil recovery. Ind. Eng. Chem. Res 2015, 54, 798-807. [CrossRef]

9. You, Q.; Wang, K.; Tang, Y.; Zhao, G.; Liu, Y.; Zhao, M.; Li, Y.; Dai, C. Study of a novel self-thickening polymer for improved oil recovery. Ind. Eng. Chem. Res. 2015, 54, 9667-9674. [CrossRef]

10. Seright, R.S.; Campbell, A.; Mozley, P.; Han, P. Stability of partially hydrolyzed polyacrylamides at elevated temperatures in the absence of divalent cations. SPE J. 2010, 15, 341-348. [CrossRef]

11. Yuan, R.; Li, Y.; Li, C.; Fang, H.; Wang, W. Study about how the metal cationic ions affect the properties of partially hydrolyzed hydrophobically modified polyacrylamide (HMHPAM) in aqueous solution. Colloids Surf. A Physicochem. Eng. Asp. 2013, 434, 16-24. [CrossRef]

12. Samanta, A.; Bera, A.; Ojha, K.; Mandal, A. Effects of Alkali, Salts, and Surfactant on Rheological Behavior of Partially Hydrolyzed Polyacrylamide Solutions. J. Chem. Eng. Data 2010, 55, 4315-4322. [CrossRef]

13. Sabhapondit, A.; Borthakur, A.; Haque, I. Characterization of acrylamide polymers for enhanced oil recovery. J. Appl. Polym. Sci. 2003, 87, 1869-1878. [CrossRef]

14. Qiu, J.; Zhang, Y.; Meng, X.; Zhang, H.; Liu, J. Synthesis and characterization of poly [acrylamide-co-(sodium 4-styrenesulfonate)] via inverse microemulsion polymerization. Polym. Int. 2010, 59, 78-84. [CrossRef]

15. Liu, X.; Jiang, W.; Gou, S.; Ye, Z.; Feng, M.; Lai, N.; Liang, L. Synthesis and evaluation of novel water-soluble copolymers based on acrylamide and modular $\beta$-cyclodextrin. Carbohydr. Polym. 2013, 96, 47-56. [CrossRef] [PubMed]

16. Irfan, M.; Seiler, M. Encapsulation using hyperbranched polymers: From research and technologies to emerging applications. Ind. Eng. Chem. Res. 2010, 49, 1169-1196. [CrossRef]

17. Yahaya, G.O.; Ahdab, A.A.; Ali, S.A.; Abu-Sharkh, B.F.; Hamad, E.Z. Solution behavior of hydrophobically associating water-soluble block copolymers of acrylamide and N-benzylacrylamide. Polymer 2001, 42, 3363-3372. [CrossRef]

18. Ye, Z.; Gou, G.; Gou, S.; Jiang, W.; Liu, T. Synthesis and characterization of a water-soluble sulfonates copolymer of acrylamide and $N$-allylbenzamide as enhanced oil recovery chemical. J. Appl. Polym. Sci. 2013, 128, 2003-2011. [CrossRef] 
19. Liu, X.; Jiang, W.; Gou, S.; Ye, Z.; Cheng, L. Synthesis and clay stabilization of a water-soluble copolymer based on acrylamide, modular $\beta$-cyclodextrin, and AMPS. J. Appl. Polym. Sci. 2013, 128, 3398-3404. [CrossRef]

20. Sabhapondit, A.; Arun Borthakur, A.; Haque, I. Water soluble acrylamidomethyl propane sulfonate (AMPS) copolymer as an enhanced oil recovery chemical. Energy Fuels 2003, 17, 683-688. [CrossRef]

21. Ye, T.; Song, Y.; Zheng, Q. Synthesis and solution property of acrylamide-sulfobetaine copolymers. Colloid Polym. Sci. 2015, 293, 797-807. [CrossRef]

22. Liu, X.J.; Jiang, W.C.; Gou, S.H.; Ye, Z.B.; Xie, X.D. Synthesis and evaluation of a water-soluble acrylamide binary sulfonates copolymer on MMT crystalline interspace and EOR. J. Appl. Polym. Sci. 2012, 125, 1252-1260. [CrossRef]

23. Mccormick, C.L.; Salazar, L.C. Water soluble copolymers: 44. Ampholytic terpolymers of acrylamide with sodium 2-acrylamido-2-methylpropanesulphonate and 2-acrylamido-2-methylpropanetrimethyl-ammonium chloride. J. Appl. Polym. Sci. 2010, 48, 1115-1120. [CrossRef]

24. Zou, C.; Gu, T.; Xiao, P.; Ge, T.; Wang, M.; Wang, K. Experimental study of cucurbit[7]uril derivatives modified acrylamide polymer for enhanced oil recovery. Ind. Eng. Chem. Res. 2014, 53, 7570-7578. [CrossRef]

25. Bai, X.; Yang, Y.; Xiao, D.; Pu, X.; Wang, X. Synthesis, characterization, and performance evaluation of the AM/AMPS/DMDAAC/SSS quadripolymer as a fluid loss additive for water-based drilling fluid. J. Appl. Polym. Sci. 2015, 132, 27-34. [CrossRef]

26. Dobrynin, A.V.; Colby, R.H.; Rubinstein, M. Polyampholytes. J. Polym. Sci. B 2004, 42, 3513-3538. [CrossRef]

27. Wang, F.; Yang, J.; Zhao, J. Understanding anti-polyelectrolyte behavior of a well-defined polyzwitterion at the single-chain level. Polym. Int. 2015, 64, 999-1005. [CrossRef]

28. Lowe, A.B.; Mccormick, C.L. Synthesis and solution properties of zwitterionic polymers. Chem. Rev. 2002, 102, 4177. [CrossRef] [PubMed]

29. Kudaibergenov, S.E. Recent advances in the study of synthetic polyampholytes in solutions. Adv. Polym. Sci. 1999, 144, 115-197.

30. He, Y.; Xu, Z.H.; Wu, F.; Luo, Z.; Chen, C.L. Synthesis and characterization of a novel amphiphilic copolymer containing $\beta$-cyclodextrin. Colloid Polym. Sci. 2014, 292, 1725-1733. [CrossRef]

31. Raffa, P.; Broekhuis, A.A.; Picchioni, F. Amphiphilic copolymers based on PEG-acrylate as surface active water viscosifiers: Towards new potential systems for enhanced oil recovery. J. Appl. Polym. Sci. 2016, 133. [CrossRef]

32. Favero, C.; Gaillard, N. Aqueous Fracturing Fluid Composition and Fracturing Process Using the Composition. U.S. Patent 9,249,352 B2, 2 February 2016.

33. Wever, D.A.Z.; Picchioni, F.; Broekhuis, A.A. Branched polyacrylamides: Synthesis and effect of molecular architecture on solution rheology. Eur. Polym. J. 2013, 49, 3289-3301. [CrossRef]

34. Zhang, R.; Yang, L.; Qin, N.; Tu, R.; Zhou, J.; Ye, Z. The swelled clay shrinkage property and inhibition of microcosmic migration in pores of quaternary ammonium salt cationic polymer. Polym. Adv. Technol. 2016, 26, 1544-1550. [CrossRef]

35. Gou, S.; Yin, T.; Ye, Z.; Jiang, W.; Yang, C.; Ma, Y.; Feng, M.; Xia, Q. High-temperature resistance water-soluble copolymer derived from acrylamide, DMDAAC, and functionalized sulfonamide for potential application in enhance oil recovery. J. Appl. Polym. Sci. 2014, 131. [CrossRef]

(C) 2017 by the authors. Licensee MDPI, Basel, Switzerland. This article is an open access article distributed under the terms and conditions of the Creative Commons Attribution (CC BY) license (http://creativecommons.org/licenses/by/4.0/). 